\title{
Visceral pleural invasion classification in non-small cell lung cancer: A proposal on the basis of outcome assessment
}

\author{
Kimihiro Shimizu, $\mathrm{MD}^{\mathrm{a}}$ \\ Junji Yoshida, $\mathrm{MD}^{\mathrm{a}}$ \\ Kanji Nagai, MD ${ }^{\mathrm{a}}$ \\ Mitsuyo Nishimura, $\mathrm{MD}^{\mathrm{a}}$ \\ Tomoyuki Yokose, $\mathrm{MD}^{\mathrm{b}}$ \\ Genichiro Ishii, MD \\ Yutaka Nishiwaki, MD
}

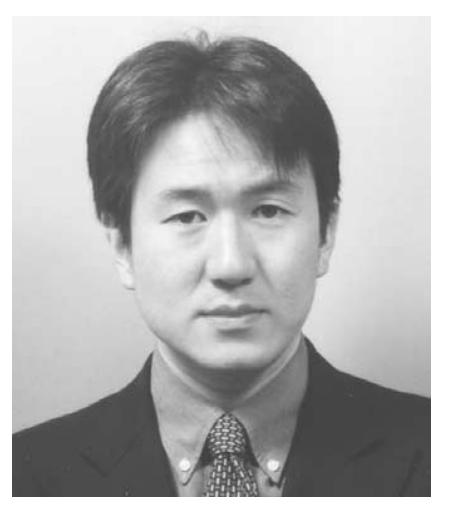

Dr Shimizu
Objective: The definition of visceral pleural invasion in lung cancer TNM classification of the International Union Against Cancer lacks detail. The purpose of this study was to evaluate the significance of the extent of pleural involvement as a prognostic factor and to propose a refined TNM classification on the basis of visceral pleural invasion.

Methods: We reviewed 1653 consecutive patients with T1, T2, and T3 surgically resected non-small cell lung cancer for their clinicopathologic characteristics and prognoses. Visceral pleural invasion was classified by using the Japan Lung Cancer Society criteria: p0, tumor with no pleural involvement beyond its elastic layer; $\mathrm{p} 1$, tumor extension beyond the elastic layer but no exposure on the pleural surface; and p2, tumor exposure on the pleural surface.

Results: The 5-year survivals for patients with $\mathrm{p} 1$ or $\mathrm{p} 2$ tumors of $3 \mathrm{~cm}$ or less were identical and significantly worse than those for patients with $\mathrm{p} 0$ tumors of the same size. Patients with $\mathrm{p} 1$ or $\mathrm{p} 2$ tumors of greater than $3 \mathrm{~cm}$ and patients with $\mathrm{T} 3$ cancers had essentially identical survivals.

Conclusions: Visceral pleural invasion should be defined as tumor extension beyond the elastic layer of the visceral pleura, regardless of its exposure on the pleural surface. A tumor of $3 \mathrm{~cm}$ or less with visceral pleural invasion should remain classified as a T2 tumor, as presently occurs in the International Union Against Cancer staging system, and tumors of greater than $3 \mathrm{~cm}$ with visceral pleural invasion should be upgraded to T3 status in the International Union Against Cancer TNM classification.

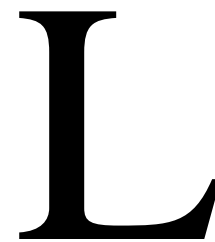

ung cancer pleural invasion was recognized as a poor prognostic factor as early as 1958 by Brewer and colleagues. ${ }^{1}$ Visceral pleural invasion (VPI) was adopted as a specific description in the TNM classification of the International Union Against Cancer (UICC) staging system in the mid-1970s ${ }^{2}$ and has remained unchanged until today: a tumor of any size that invades the visceral pleura is classified as T2. Although a tumor of $3 \mathrm{~cm}$ or less is upgraded to T2, a tumor of greater than $3 \mathrm{~cm}$ remains $\mathrm{T} 2$ in this system if a tumor has VPI.

The UICC TNM classification describes little on VPI definition. The Japan Lung Cancer Society (JLCS) classifies VPI as follows: p0, tumor with no pleural involvement beyond its elastic layer; $\mathrm{p} 1$, tumor that extends beyond the elastic layer of the visceral pleura but is not exposed on the pleural surface; $\mathrm{p} 2$, tumor that is exposed 
TABLE 1. Patient characteristics

\begin{tabular}{|c|c|c|c|c|c|}
\hline \multirow[b]{2}{*}{ Characteristics } & \multicolumn{5}{|c|}{ No. of patients $(\%)$} \\
\hline & po & p1 & p2 & T3 & Total \\
\hline \multicolumn{6}{|l|}{ Age (y) } \\
\hline Mean $\pm S D$ & $64 \pm 10$ & $66 \pm 9$ & $63 \pm 10$ & $63 \pm 10$ & $63 \pm 10$ \\
\hline Range & $30-85$ & $42-89$ & $35-85$ & $34-83$ & $30-89$ \\
\hline Sex (male/female) & $662 / 393$ & $177 / 94$ & $34 / 47$ & $212 / 34$ & $1085 / 568$ \\
\hline \multicolumn{6}{|l|}{ Type of operation } \\
\hline Segmentectomy & $21(2)$ & $5(2)$ & $0(0)$ & $3(1)$ & $29(2)$ \\
\hline Lobectomy & $993(94)$ & 254 (94) & $79(98)$ & $186(76)$ & $1512(91)$ \\
\hline Pneumonectomy & $41(4)$ & $12(4)$ & $2(3)$ & $57(23)$ & $112(7)$ \\
\hline \multicolumn{6}{|l|}{ Histology } \\
\hline Adenocarcinoma & $679(64)$ & $163(60)$ & $70(87)$ & $85(35)$ & $997(60)$ \\
\hline Squamous cell carcinoma & $311(30)$ & $75(28)$ & $9(11)$ & $118(48)$ & $513(31)$ \\
\hline Large cell carcinoma & $36(3)$ & $20(7)$ & $2(3)$ & $21(9)$ & $79(5)$ \\
\hline Adenosquamous carcinoma & $29(3)$ & $13(5)$ & $0(0)$ & $22(9)$ & $42(4)$ \\
\hline \multicolumn{6}{|l|}{ Size } \\
\hline$\leq 3 \mathrm{~cm}$ & $624(59)$ & $107(40)$ & $33(41)$ & $38(15)$ & $802(49)$ \\
\hline$>3 \mathrm{~cm}$ & $431(41)$ & $164(60)$ & $48(59)$ & $208(85)$ & $851(51)$ \\
\hline \multicolumn{6}{|l|}{ Pathologic } \\
\hline no & $795(75)$ & $163(60)$ & $44(54)$ & $110(45)$ & $1112(67)$ \\
\hline $\mathrm{n} 1$ & $134(13)$ & $46(17)$ & $9(11)$ & $62(25)$ & $251(15)$ \\
\hline $\mathrm{n} 2$ & $126(12)$ & $62(23)$ & $28(35)$ & $74(30)$ & $290(18)$ \\
\hline Total & 1055 & 271 & 81 & 246 & 1653 \\
\hline
\end{tabular}

Numbers in parentheses are percentages. $n 0$, No regional lymph node metastasis; $n 1$, metastasis to ipsilateral peribronchial hilar lymph nodes, ipsilateral hilar lymph nodes, or both, and intrapulmonary nodes, including involvement by direct extension of the primary tumor; n2, metastasis to ipsilateral mediastinal lymph nodes, subcarinal lymph nodes, or both.

on the pleural surface but does not involve adjacent anatomic structures; and p3, tumor that involves adjacent anatomic structures. ${ }^{3}$ The Society classifies a p2 tumor of any size as T2 and a p1 tumor of $3 \mathrm{~cm}$ or less as T1. The UICC TNM classification does not clarify whether VPI includes $\mathrm{p} 1$. Given that $\mathrm{p} 1$ pleural involvement is interpreted as VPI in the UICC classification, there appears to be an inconsistency in the T1/T2 definition between the UICC and JLCS TNM classifications. To the best of our knowledge, there have been no studies reported on $\mathrm{p} 1$ pleural involvement as a prognostic factor.

The purpose of this study was to evaluate the significance of $\mathrm{p} 1$ pleural involvement as a prognostic factor and to propose a refined TNM classification on the basis of VPI.

\section{Patients and Methods}

From February 1979 through March 2001, 1653 consecutive patients with T1, T2, or T3 non-small cell lung cancer underwent pulmonary resection (segmentectomy or more) and systematic mediastinal lymph node dissection at our institution, as described previously. ${ }^{4}$ All these patients had curative resection, which was defined as complete removal of ipsilateral hilar and mediastinal lymph nodes together with the primary tumor. Patients who had induction chemotherapy or radiotherapy and patients with evidence of residual tumor at the surgical margin, malignant effusion, satellite lesion, or distant metastasis verified intraoperatively or by means of postoperative pathologic examination were excluded from this study. Patients were pathologically staged on the basis of the UICC TNM classification. ${ }^{2}$ Patient characteristics are shown in Table 1.

Histopathologic studies were done according to the World Health Organization criteria, ${ }^{5}$ and VPI was reviewed in detail. Tumor sections were stained with hematoxylin and eosin and Victoria-blue van Gieson stains. VPI was classified according to the JLCS criteria ${ }^{3}$ : p0; tumor with no pleural involvement beyond its elastic layer; p1, tumor that extends beyond the elastic layer of the visceral pleura but is not exposed on the pleural surface (Figure $1, A)$; and $\mathrm{p} 2$, tumor that is exposed on the pleural surface but does not involve adjacent anatomic structures (Figure 1,B). All patients were divided into 7 groups, A to $G$, according to the tumor diameter ( $\leq 3 \mathrm{~cm}$ or $>3 \mathrm{~cm})$, VPI (p0, p1, or p2), and T3 factor, as shown in Table 2 .

We analyzed the overall survival of patient groups A to G. We also evaluated survival of patients without lymph node involvement (n0) in each group. Survival was estimated by using the Kaplan-Meier method, ${ }^{6}$ and differences in survival were determined by means of log-rank analysis. ${ }^{7}$ Zero time was the date of pulmonary resection, and the terminal event was defined as any death.

\section{Results}

\section{Patient Characteristics and VPI}

Table 1 shows the patient characteristics. There were 568 women and 1085 men aged 30 to 89 years (mean, 63 years; median, 65 years). Extents of pulmonary resection were pneumonectomy $(\mathrm{n}=112)$, lobectomy $(\mathrm{n}=1512)$, and 

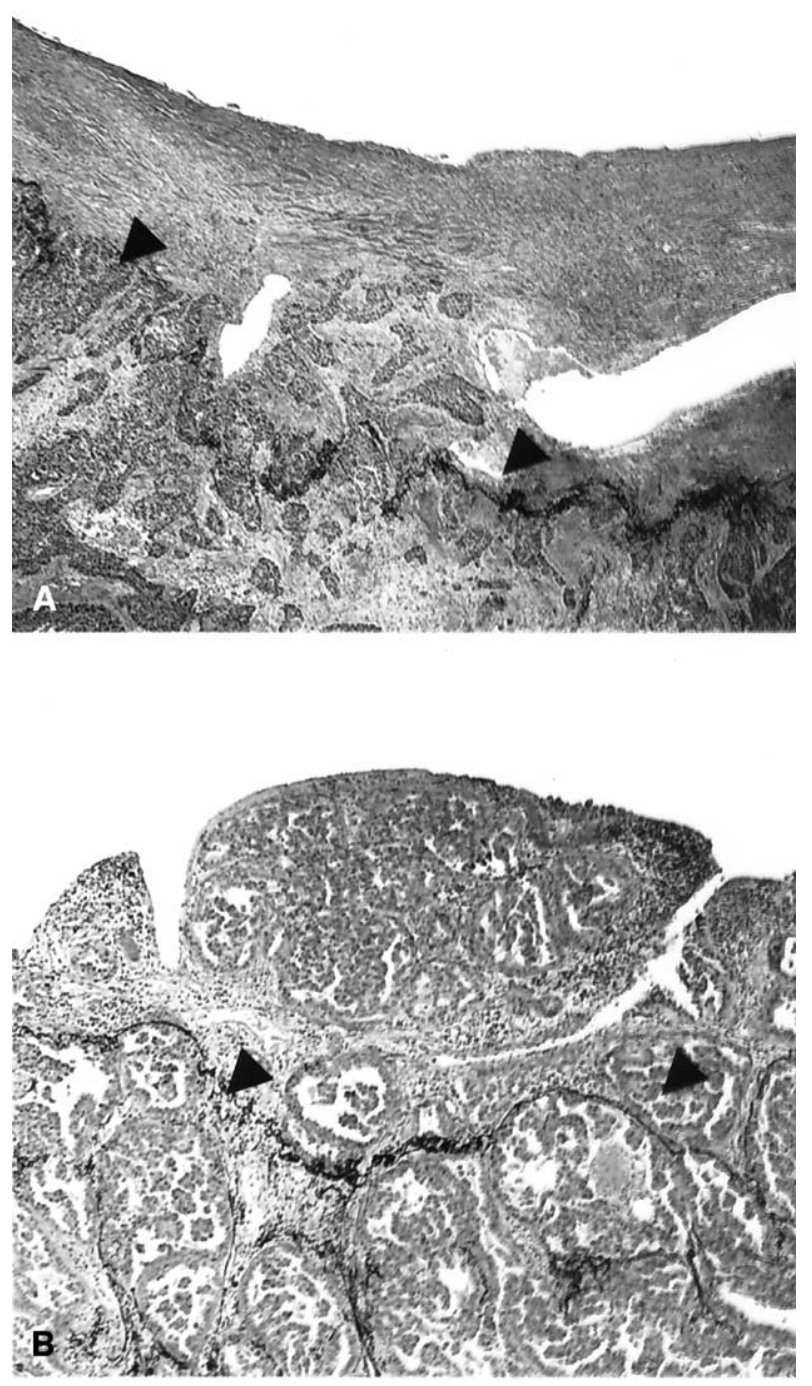

Figure 1. A, Tumor cells extend beyond the visceral pleural elastic layer (arrowheads) but are not exposed on the pleural surface: p1. B, Tumor cells extend beyond the visceral pleural elastic layer (arrowheads) and are exposed on the pleural surface but do not involve the parietal pleura: $\mathbf{p 2}$.

segmentectomy $(\mathrm{n}=29)$. Histologic types were adenocarcinoma $(\mathrm{n}=997)$, squamous cell carcinoma $(\mathrm{n}=513)$, large cell carcinoma $(\mathrm{n}=79)$, and adenosquamous carcinoma $(\mathrm{n}=64)$.

\section{Survival Difference}

The overall 5-year survivals for groups A through $\mathrm{G}$ were $79 \%, 63 \%, 42 \%, 60 \%, 39 \%, 35 \%$, and $36 \%$, respectively (Figures 2 and 3). The difference in survival between groups $\mathrm{A}$ and $\mathrm{B}$, between groups $\mathrm{A}$ and $\mathrm{C}$, between groups $\mathrm{B}$ and $\mathrm{G}$, and between groups $\mathrm{C}$ and $\mathrm{G}$ (Figure 2) and the difference in survival between groups $\mathrm{D}$ and $\mathrm{E}$ and between
TABLE 2. Seven groups according to tumor diameter, VPI, and $\mathrm{T} 3$ factor

\begin{tabular}{ccccc}
\hline Group & $\begin{array}{c}\text { Tumor size } \\
\text { diameter }\end{array}$ & VPI p-factor* & $\begin{array}{c}\text { All patients, } \\
\text { n (\%) }\end{array}$ & $\begin{array}{c}\text { Patients with } \\
\text { n0 disease, } \\
\text { n (\%) }\end{array}$ \\
\hline A & $\leq 3 \mathrm{~cm}$ & p0 & $624(38)$ & $507(46)$ \\
B & $\leq 3 \mathrm{~cm}$ & p1 & $107(7)$ & $79(7)$ \\
C & $\leq 3 \mathrm{~cm}$ & p2 & $33(2)$ & $23(2)$ \\
D & $>3 \mathrm{~cm}$ & p0 & $431(26)$ & $288(26)$ \\
E & $>3 \mathrm{~cm}$ & p1 & $164(10)$ & $84(8)$ \\
F & $>3 \mathrm{~cm}$ & p2 & $48(3)$ & $21(2)$ \\
G & Patients with T3 tumors & $246(15)$ & $110(10)$ \\
& as defined by the UICC & & \\
& TNM classification & &
\end{tabular}

VPI, Visceral pleural invasion; UICC, International Union Against Cancer. *The Japan Lung Cancer Society classification of visceral pleura invasion.

groups D and F (Figure 3) were significant. In contrast, the survival curves for groups B and D almost overlapped with each other, and there was no statistically significant difference in survival between the groups (Figure 2). Similarly, there was no statistically significant difference in survival between groups $\mathrm{C}$ and $\mathrm{D}$ and between groups $\mathrm{B}$ and $\mathrm{C}$ (Figure 2), nor was there a significant difference in survival between groups $\mathrm{E}$ and $\mathrm{F}$ (Figure 3). Also, the differences in survival between groups $\mathrm{E}$ and $\mathrm{G}$ and between groups $\mathrm{F}$ and $\mathrm{G}$ were not significant (Figure 3). Outcomes were also examined in the $\mathrm{n} 0$ patient cohort, and similar relationships were observed.

\section{Discussion}

The JLCS classifies VPI into 4 groups (p0, p1, p2, and p3), whereas in the UICC classification $\mathrm{p} 1$ and $\mathrm{p} 2$ involvements are not distinguished. If $\mathrm{p} 1$ pleural involvement is interpreted as VPI in the UICC classification, there appears to be inconsistency in the T1/T2 definition between the UICC and JLCS TNM classification.

Brewer and colleagues, ${ }^{1}$ Ichinose and coworkers, ${ }^{8}$ and Manac'h and associates ${ }^{9}$ demonstrated that pleural invasion is an important poor prognosis factor. In their reports, however, p1 and p2 invasions were combined and analyzed as a single VPI category. In our study we conducted uniform hematoxylin and eosin and Victoria-blue van Gieson staining on all tumors and performed histologic review in all cases, with special interest in VPI and its JLCS subclassifications, $\mathrm{p} 0, \mathrm{p} 1$, and $\mathrm{p} 2$. We retrospectively analyzed postoperative survival in patients with $\mathrm{p} 0, \mathrm{p} 1, \mathrm{p} 2$, or T3 cancer to evaluate the significance of pleural involvement extent as a prognostic factor.

In our series the 5-year survivals for the patients with $\mathrm{p} 1$ or $\mathrm{p} 2$ tumors of $3 \mathrm{~cm}$ or less were identical and significantly worse than those for patients with $\mathrm{p} 0$ disease with the same 


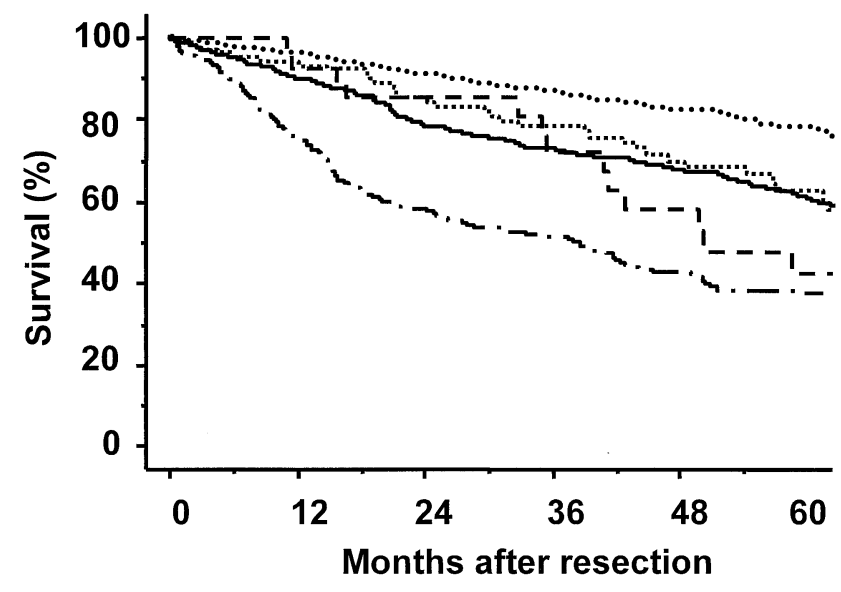

patients (n) 5- year survival (\%) p-value*

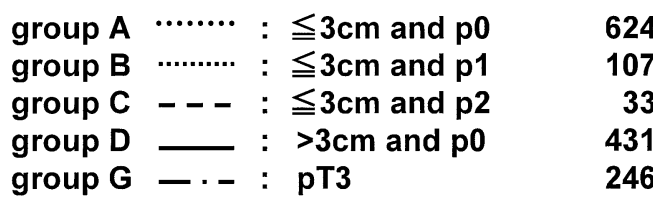

\begin{tabular}{|c|c|}
\hline 79 & $\neg<0.01$ \\
\hline 63 & 0.20 \\
\hline 42 & 0.82 \\
\hline 36 & $<0.01$ \\
\hline
\end{tabular}

*: $p$-value by log-rank test

Figure 2. Survival curves and overall 5-year survivals for groups $A, B, C, D$, and $G$. The differences in survival between groups $A$ and $B$, between groups $A$ and $C(P<.01)$, between groups $B$ and $G(P<.01)$, between groups $C$ and $G(P=.04)$, and between groups $D$ and $G$ were significant. There was no statistically significant difference in survival between groups $B$ and $C$, between groups $B$ and $D(P=.38)$, and between groups $C$ and $D$.
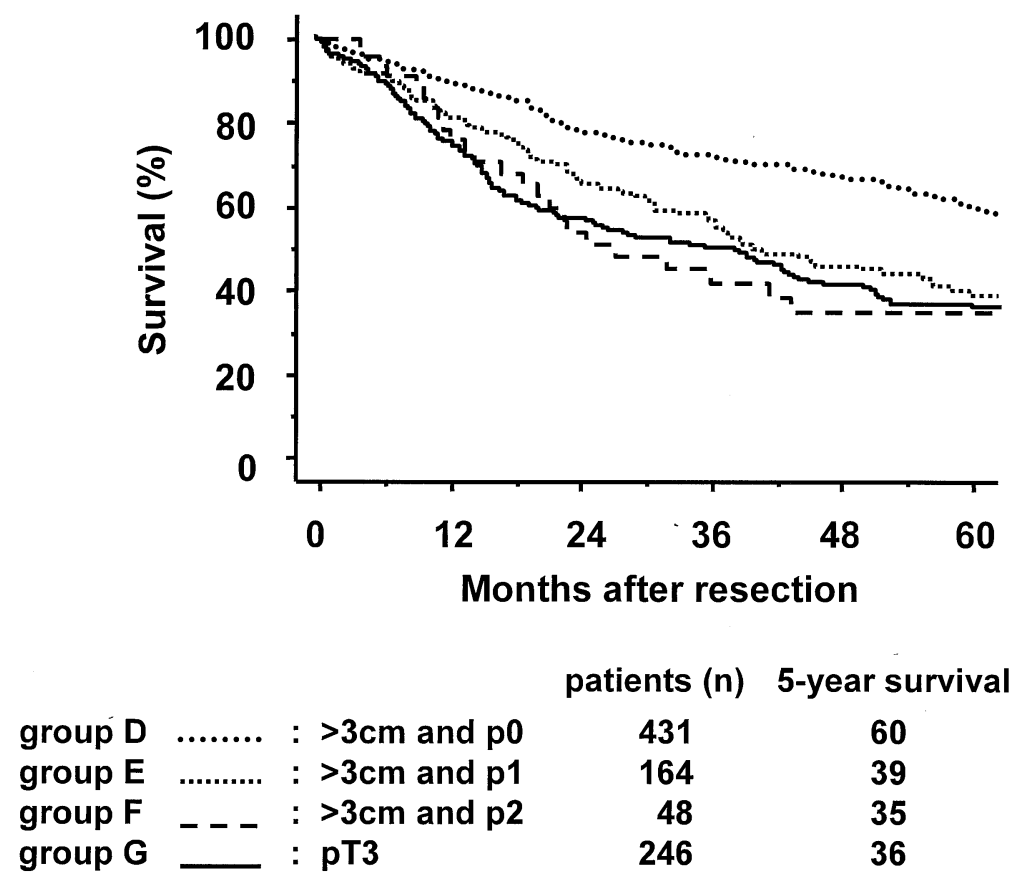

$\begin{array}{ccc}\text { patients (n) } & \text { 5-year survival (\%) } & p \text {-value* } \\ 431 & 60 & ]<0.01 \\ 164 & 39 & ] 0.47 \\ 48 & 35 & ] 0.90 \\ 246 & 36 & \end{array}$

\section{*: $p$-value by log-rank test}

Figure 3. Survival curves and overall 5-year survivals for groups $D, E, F$, and $G$. The differences in survival between groups $D$ and $E$, between groups $D$ and $F(P<.01)$, and between groups $D$ and $G(P<.01)$ were significant. There was no statistically significant difference in survival between groups $E$ and $F$, between groups $E$ and $G(P=.38)$, and between groups $F$ and $G$. 
TABLE 3. Difference between the UICC, the JLCS, and our proposed new classifications

\begin{tabular}{lcccc}
\hline Classification & $\begin{array}{c}\mathbf{3} \mathbf{~ c m} \\
\text { without VPI }\end{array}$ & $\begin{array}{c}\mathbf{3} \mathbf{~ c m} \\
\text { with VPI }\end{array}$ & $\begin{array}{c}\mathbf{3} \mathbf{~ c m} \\
\text { without VPI }\end{array}$ & $\mathbf{3} \mathbf{~ c m}$ \\
wiCC & $\mathrm{T} 1$ & $\mathrm{~T} 2$ & $\mathrm{~T} 2$ & $\mathrm{~T}$ \\
JLCS & $\mathrm{T} 1\left(\mathrm{p} 0^{*}\right)$ & $\mathrm{T} 1\left(\mathrm{p} 1^{*}\right) \mathrm{T} 2\left(\mathrm{p} 2^{*}\right)$ & $\mathrm{T} 2\left(\mathrm{p} 0^{*}\right)$ & $\mathrm{T} 2$ \\
Ours & $\mathrm{T} 1$ & $\mathrm{~T} 2$ & $\mathrm{~T} 2$ & $\mathrm{~T} 2\left(\mathrm{p} 1 / 2^{*}\right)$ \\
\hline
\end{tabular}

UICC, International Union Against Cancer; JLCS, Japan Lung Cancer Society; VPI, visceral pleura invasion.

${ }^{*}$ The Japan Lung Cancer Society classification of visceral pleura invasion.

size cancers. Similarly, the 5-year survivals for patients with p1 or 22 tumors greater than $3 \mathrm{~cm}$ were identical, whereas they were notably worse than those in patients with $\mathrm{p} 0$ disease with the same size cancers. Furthermore, there was no statistically significant difference in survival between the patients with $\mathrm{p} 1$ or $\mathrm{p} 2$ tumors greater than $3 \mathrm{~cm}$ and the patients with T3 cancers. Similar relationships were observed among patients with $\mathrm{n} 0$ disease.

These results indicate that $\mathrm{p} 1$ and $\mathrm{p} 2$ pleural involvement should be combined as a single category as VPI. A tumor of $3 \mathrm{~cm}$ or less with p1 involvement should, unlike the JLCS classification, be classified as T2. Although the UICC classifies a tumor of greater than $3 \mathrm{~cm}$ as $\mathrm{T} 2$ regardless of pleural involvement, our results suggest $\mathrm{p} 1$ or $\mathrm{p} 2$ tumors of greater than $3 \mathrm{~cm}$ should be upgraded to T3 status (Table 3).

In conclusion, this study indicates that VPI should be defined as tumor extension beyond the elastic layer of the visceral pleura, regardless of its exposure on the pleural surface. A tumor of $3 \mathrm{~cm}$ or less with VPI should remain a T2 tumor, as presently occurs in the UICC staging system (but upgraded in the JLCS staging system to match the UICC system), and tumors of greater than $3 \mathrm{~cm}$ with VPI should be upgraded to T3 status in both staging systems. This modification would make the non-small cell lung cancer TNM classification system simpler and cleaner.
We thank Professor J. Patrick Barron (International Medical Communication Center, Tokyo Medical University) for reviewing the English manuscript.

\section{References}

1. Brewer LA, Bai AF, Little JN, Pardo GR. Carcinoma of the lung: practical classification of early diagnosis and survival treatment. JAMA. 1958;166:1149-54.

2. Mountain CF. Revisions in the International System for Staging Lung Cancer. Chest. 1997;111:1710-7.

3. The Japan Lung Cancer Society. General rule for clinical and pathological record of lung cancer. [in Japanese]. 5th ed. Tokyo: Kanehara; 1999.

4. Naruke T, Suemasu K, Ishikawa S. Surgical treatment for lung cancer with metastasis to mediastinal lymph nodes. J Thorac Cardiovasc Surg. 1976;71:279-85.

5. World Health Organization. The World Health Organization histological typing of lung tumors. 3rd ed. Geneva: World Health Organization; 1999.

6. Kaplan EL, Meier P. Non parametric estimation from incomplete observations. J Am Stat Assoc. 1958;53:457-81.

7. Peto R, Peto J. Asymptomatically efficient rank invariant test procedures. J R Stat Soc [A]. 1972;135:185-207.

8. Ichinose Y, Yano T, Asoh H, Yokoyama H, Yoshino I, Katsuda Y. Prognostic factors obtained by a pathologic examination in completely resected non small-cell lung cancer. An analysis in each pathologic stage. J Thorac Cardiovasc Surg. 1995;110:601-5.

9. Manac'h D, Riquet M, Medioni J, Le Pimpec-Barthes F, Dujon A, Danel C. Visceral pleura invasion by non-small cell lung cancer: an underrated bad prognostic factor. Ann Thorac Surg. 2001;71:1088-93. 